\title{
Article \\ Bacteriological quality assessment of buffalo meat collected from different districts of Bangladesh with particular emphasis on the molecular detection and antimicrobial resistance of the isolated Salmonella species
}

\author{
Mahedi Hasan ${ }^{1}$, S. M. Lutful Kabir ${ }^{1 *}$, Md. Tanvir Rahman ${ }^{1}$ and Yousuf Ali Sarker ${ }^{2}$ \\ ${ }^{1}$ Department of Microbiology and Hygiene, Bangladesh Agricultural University, Mymensingh-2202, \\ Bangladesh \\ ${ }^{2}$ Department of Pharmacology, Bangladesh Agricultural University, Mymensingh-2202, Bangladesh
}

*Corresponding author: Professor Dr. S. M. Lutful Kabir, Department of Microbiology and Hygiene, Bangladesh Agricultural University, Mymensingh-2202, Bangladesh. Phone: +8801754987218; E-mail: lkabir79@gmail.com, lkabir79@bau.edu.bd

Received: 07 May 2018/Accepted: 24 May 2018/ Published: 31 May 2018

\begin{abstract}
The research project was conducted to assess the bacteriological quality of buffalo meat samples collected from three upazilas namely Haluaghat, Sreepur and Madhupur of Bangladesh under the districts of Mymensingh, Gazipur and Tangail respectively with particular emphasis on the molecular detection and antimicrobial resistance of the isolate Salmonella species. Total viable count (TVC), total staphylococcal count (TStaC) and total salmonella count (TSC) of meat samples were determined and the mean values of TVC, TStaC and TSC for the Haluaghat, Sreepur and Madhupur were $\log 8.30, \log 7.94, \log 8.15 ; \log 6.21, \log 6.40$, $\log 5.43$ and $\log 4.76, \log 4.82, \log 4.56 \mathrm{CFU} / \mathrm{gm}$ respectively which exceeded the ICMSF recommendations values. The variation of TVC and TSC in meats of different buffalo markets was significant at $5 \%$ level where the variation of TStaC was significant at $1 \%$ level. Nevertheless no significant variation was demonstrated between the interactions of the three upazilas. Among the samples, $46.67 \%(n=14)$ were found to be associated with Salmonella spp. The Salmonella spp. were identified by observing black centered colonies on XLD agar, positive to MR test and negative to VP and Indole test. All isolates of Salmonella spp. were positive to 16s rRNA gene based PCR (574bp). All isolates of Salmonella species were susceptible to ciprofloxacin, streptomycin and gentamicin. All isolates of Salmonella spp. $(\mathrm{n}=14 ; 100 \%)$ were resistant to amoxicillin and few isolates also resistant to erythromycin, tetracycline, azithromycin and cephradine. The findings of this study revealed the presence of multidrug resistant Salmonella spp. in buffalo meat of Mymensingh, Gazipur and Tangail districts of Bangladesh that posseses a serious threat to public health.
\end{abstract}

Keywords: buffalo meat; bacteriological assessment; Salmonella; antimicrobial resistance

\section{Introduction}

Consumption of unsafe, contaminated food leads to food-borne diseases, which cause considerable morbidity and mortality in consumer. The annual incidence of 1.5 billion episodes of diarrhea in children less than 5 years of age, and the more than 3 million resultant deaths are an indication of the magnitude of unsafe food (NIH, 2006). Recently, food safety has become extremely important and ensuring products safety is an international public health concern as well as in Bangladesh. Meat and meat products are important sources of zoonotic infections caused by a variety of bacteria, viruses and parasites (Smith, 2003). More than 90 percent of the cases of food poisoning each year are caused by Staphylococcus aureus, Salmonella spp., Clostridium perfringens, Campylobacter spp., Listeria monocytogenes, Vibrio parahaemolyticus, Bacillus cereus, Entero-pathogenic Escherichia coli, and Shigella spp. The initial level of post productive contamination as well as the numerous intrinsic and extrinsic parameters of product determine its microbiological stability and consequently affect the 
safety of consumer causes serious long-term health effect of food borne hazards (Komba et al., 2012). Medical records in Bangladesh revealed that a large number of patients from local area suffered from food borne disease. This information has given us impetus to generate data related to the occurrence and frequency of microbial load in meat. A great diversity of microbes inhabits fresh meat generally, but different types may become dominant depending on $\mathrm{pH}$, composition, textures, storage temperature, and transportation means (Ercolini et al., 2006). The meat available at retail outlets comes through a long chain of slaughtering, and transportation, where each step may pose a risk of microbial contamination. The sanitary conditions of abattoirs and its surrounding environment are major factors contributing in bacterial contamination of meat (Gill et al., 2000). Buffalo meat is one of the important sources of meat in Bangladesh and in some region of it is most preferable than other types of meat (Faruque et al., 1990). There are approximately 1.471 million buffaloes in Bangladesh which are not found in all farm families; rather they are raised by rich and medium farmers and found in the particular agro-ecological zones (DLS, 2015). Foodborne diseases caused by non-typhoid Salmonella represent an important public health problem worldwide. In underdeveloped countries, there are more than one billion cases of gastroenteritis and up to 5 million deaths annually (Gould and Russell, 2003). In the United States alone, an estimated 1.4 million cases of salmonellosis is thought to occur annually, of which about 200000 cases are reported to the CDC (Lynch et al., 2006). Salmonella infection accounts for $30 \%$ of deaths resulting from foodborne illnesses in the USA and the most commonly isolated serovars are Typhimurium and Enteritidis (CDC, 2007). A variety of foods have been implicated as vehicles transmitting salmonellosis to humans (Kariuki et al., 2006). Young children, the elderly and patients with chronic illnesses or immune-compromised systems are particularly susceptible to salmonellosis (Bell and Kyriakides, 2002). There are many regulatory agencies responsible for ensuring food safety and quality assurance which are offered to the consumers that will be pure, healthful and of quality claimed such agencies belonging to International forum include the FAO, WHO, UNICEF and CAC. There are only few reports of incidence of Salmonella and Staphylococcas in retail raw buffalo meat (Sen and Garode, 2016; Singh et al., 2015; Sychanh et al., 2013). However, there was no report on bacteriological study of buffalo meat samples in Bangladesh. So the research project systematically assessed the microbial load; total viable count (TVC), total staphylococcal count (TStaC) and total salmonella count (TSC), isolation and identification of Salmonella spp., and determination of antibiotic susceptibility and resistance patterns of Salmonella spp. against eight antibiotics from raw buffalo meat at abattoirs and retail outlets in different areas of three upazilasnamely Madhupur, Sreepur and Haluaghat under the districts of Tangail, Gazipur and Mymensingh respectively.

\section{Materials and Methods}

\subsection{Collection and transportation of samples}

A total number of 30 meat samples (10 gm of buffalo thigh muscle) were collected equally from three upazilas namely Madhupur, Sreepur and Haluaghat under three districts namely Tangail, Gazipur and Mymensingh respectively. After collection, immediately brought to Bacteriology Laboratory of the Department of Microbiology and Hygiene, Bangladesh Agricultural University, Mymensingh through maintaining cool chain using ice box.

\subsection{Enumeration of TVC, TStaC and TSC}

For the determination of total bacterial count, $0.1 \mathrm{ml}$ of each ten-fold dilution was transferred and spread on duplicate plate count agar (PCA) using a fresh pipette for each dilution. The diluted samples were spread as quickly as possible on the surface of the plate with a sterile glass spreader. One sterile spreader was used for each plate. The plates were then kept in an incubator at $37^{\circ} \mathrm{C}$ for $24-48$ hours. Following incubation, plates exhibiting 30-300 colonies were counted. The average number of colonies in a particular dilution was multiplied by the dilution factor to obtain the total viable count. The total viable count was calculated according to ISO (1995). The results of the total bacterial count were expressed as the number of organism or colony forming units per gram $(\mathrm{CFU} / \mathrm{g})$ of meat sample.

In case of TStaC and TSC, the procedures of sampling, dilution and streaking were similar to those followed in TVC. Mannitol salt agar (MSA) and xylose lysine deoxycholateagar (XLDA) were used for TStaC and TSC respectively. The calculation also similar to that of total viable count.

\subsection{Isolation and identification of bacteria}

Bacteriological analysis was done according to the standard method (ICMSF, 1985). The examination followed detail study of colony characteristics including the morphological and biochemical properties. In order to find out different types of microorganisms in samples well isolated individual of bacterial colonies were fished out in 
pure culture from the PCA, MSA, and XLDA, subsequently identified according to the Bergey's manual of determinative bacteriology (1994). The isolated organisms with supporting growth characteristics on various media were subjected to different biochemical tests; sugar fermentation test for acid or acid and gas, indole production test, catalase test, coagulase test, methyl-red and Voges-Proskauer (VP) test. In all cases standard methods as described by Cowan (1985) were followed for conducting these tests.

\subsection{Molecular identification by polymerase chain reaction (PCR)}

DNA template was prepared by boiling method as described by (Queipo-Ortuño et al., 2007). All the samples were examined by two pairs of primers (Table 1) to detect 16S rRNA gene of Salmonella spp. The PCR reactions were carried out using a thermocycler (ASTEC, Japan) with the following programme: initial denaturation with 1 cycle of $5 \mathrm{~min}$ at $94^{\circ} \mathrm{C}, 35$ cycles each consisting of denaturation with 20 seconds at $94^{\circ} \mathrm{C}$, annealing with 30 secondsat $50^{\circ} \mathrm{C}$, extension with 30 seconds at $72^{\circ} \mathrm{C}$ and a final extension step of 5 min at $72^{\circ} \mathrm{C}$. PCR products were separated on $1.5 \%$ agarose gel, stained with ethidium bromide and photographed using a gel documentation system (BioRad).

\subsection{Antibiotic sensitivity test}

All isolates that were tested for antimicrobial drug susceptibility against eight commonly used antibiotics by disc diffusion method as described by Bauer et al. (1966). For this purpose, eight different antibiotic discs were obtained from commercial sources (Himedia, India). The selected antibiotics used were ciprofloxacin (5 $\mu \mathrm{g} / \mathrm{disc})$, azithromycin $(30 \mu \mathrm{g} / \mathrm{disc})$, amoxicillin $(30 \mu \mathrm{g} / \mathrm{disc})$, gentamicin $(10 \mu \mathrm{g} / \mathrm{disc})$, Cephradine $(25 \mu \mathrm{g} / \mathrm{disc})$, erythromycin $(30 \mu \mathrm{g} / \mathrm{disc})$, streptomycin $(10 \mu \mathrm{g} / \mathrm{disc})$, and tetracycline $(30 \mu \mathrm{g} / \mathrm{disc})$. The interpretation on susceptibility was done according to the guidelines of Clinical and Laboratory Standard Institute (CLSI, 2007) formerly known as NCCLS.

\subsection{Statistical analysis}

The data on total viable count (TVC), total staphylococcal count (TStaC) and total salmonella count (TSC) obtained from the bacteriological examination of meat samples of the buffalo carcass collected from different selected upazila of Bangladesh were analyzed in completely randomized design (CRD) using computer package subjected to Analysis of Variance using SPSS Software (Version 16, 2007). The differences between means were evaluated by Duncan's Multiple Range Test (Gomez and Gomez, 1984). Correlation between TVC, TStaC and TSC were also evaluated.

Table 1. Primers used in this study.

\begin{tabular}{lllll}
\hline Primer & Sequence (5'-3') & Target gene & $\begin{array}{l}\text { Amplicon } \\
\text { size (bp) }\end{array}$ & Reference \\
\hline $\begin{array}{l}\text { Sal 16S rRNA F } \\
\text { Sal 16S rRNA R }\end{array}$ & TGTTGTGGTTAATAACCGCA & $\begin{array}{l}\text { Salmonella 16S } \\
\text { rRNA gene }\end{array}$ & 574 & $\begin{array}{l}\text { Lin and Tsen } \\
(1996)\end{array}$ \\
\hline
\end{tabular}

\section{Results}

\subsection{Results of TVC, TStaC and TSC}

The mean and standard deviation of the total viable count (TVC) in buffalo thigh meats of Haluaghat, Sreepur and Madhupur were $\log 8.30 \pm 0.30, \log 7.94 \pm 0.31$ and $\log 8.15 \pm 0.28 \mathrm{CFU} / \mathrm{gm}$ respectively (Tables 2). The results of total viable count in three different retail markets were differed significantly $(\mathrm{P}<0.05)$. The maximum and minimum range of TVC in thigh meat recorded at Haluaghat, Sreepur and Madhupur were $\log 8.8, \log 8.32$, $\log 8.47$ and $\log 7.79, \log 7.52, \log 7.42$ respectively (Table 3). However the average value of TVC at three upazila are $\log 8.30, \log 7.94$ and $\log 8.15$ as shown in Table 3. In Sreepur the value of TVC was lower than Madhupur but it is highest in Haluaghat.

The mean and standard deviation of the total staphylococcal count (TStaC) in buffalo thigh meats of Haluaghat, Sreepur and Madhupur were $\log 6.21 \pm 0.29, \log 6.40 \pm 0.13$ and $\log 5.43 \pm 0.53$ CFU/gm respectively (Tables 2). The result of total staphylococcal count in three different retail markets were differed significantly $(\mathrm{P}<0.01)$. The maximum and minimum range of TStaC in thigh meat recorded at Haluaghat, Sreepur and Madhupur were $\log 6.99, \log 6.63, \log 6.25$ and $\log 5.99, \log 6.21, \log 4.98$ respectively (Table 3 ). However, the average value of TStaC at three upazilas are $\log 6.21, \log 6.40$ and $\log 5.43$ as shown in Table 3. In Madhupur the value of TStaC was lower than Haluaghat but it is highest in Sreepur. 
The mean and standard deviation of the total salmonella count (TSC) in buffalo thigh meats of Haluaghat, Sreepur and Madhupur were $\log 4.76 \pm 0.46, \log 4.82 \pm 0.39$ and $\log 4.56 \pm 0.37$ CFU/gm respectively (Tables 2). Nevertheless no significant variation was demonstrated between the interactions of the three upazilas. The results of total salmonella count in three different retail markets were not differed significantly $(\mathrm{P}>0.05)$. The maximum and minimum range of TSC in thigh meat recorded at Haluaghat, Sreepur and Madhupur were log 5.74, $\log 5.16, \log 5.26$ and $\log 4.08, \log 4.13, \log 4.29$ respectively (Table 3). However, the average values of TSC at three upazilas are $\log 4.76, \log 4.82$ and $\log 4.56$ as shown in Table 3. In Madhupur the value of TSC was lower than Haluaghat but it is highest in Sreepur.

Table 2. Determination of mean and standard deviation for microbiological quality of buffalo meat samples at different upazilas of Bangladesh.

\begin{tabular}{llll}
\hline Upazila & TVC $($ Mean \pm SD) & TStaC $($ Mean \pm SD) & TSC $($ Mean \pm SD) \\
\hline Haluaghat & $8.30 \pm 0.30^{\mathrm{a}}$ & $6.21 \pm 0.29^{\mathrm{a}}$ & $4.76 \pm 0.46^{\mathrm{a}}$ \\
Sreepur & $7.94 \pm 0.31^{\mathrm{b}}$ & $6.40 \pm 0.13^{\mathrm{a}}$ & $4.82 \pm 0.39^{\mathrm{a}}$ \\
Madhupur & $8.15 \pm 0.28^{\mathrm{a}}$ & $5.43 \pm 0.53^{\mathrm{b}}$ & $4.56 \pm 0.37^{\mathrm{a}}$ \\
LSD & 0.813 & 0.669 & 0.827 \\
Level of Sig. & $*$ & $* *$ & NS \\
\hline
\end{tabular}

$*=$ Single asterisk $(*)$ means significant at $5 \%$ level of probability; $* *=$ Double asterisk $(* *)$ means significant at $1 \%$ level of probability; NS = Not significant

In a column figures with same letter do not differ significantly $(\mathrm{p}>0.05)$ whereas figures with dissimilar letter differ significantly (as per DMRT).

TVC $=$ Total Viable Count; TStaC $=$ Total Staphylococcal Count; TSC $=$ Total Salmonella Count; LSD= Least Significant Difference

All counts are expressed in logarithms and CFU/g of meat.

Table 3. Range of total viable bacteria, staphylococcal and salmonella count in Buffalo meats obtained from Haluaghat, Sreepur and Madhupur of three districts.

\begin{tabular}{|c|c|c|c|c|c|c|c|c|c|c|}
\hline \multirow{2}{*}{$\begin{array}{l}\text { Source of } \\
\text { collection }\end{array}$} & \multirow{2}{*}{$\begin{array}{l}\text { Region of } \\
\text { carcass } \\
\text { examined }\end{array}$} & \multicolumn{3}{|c|}{ TVC } & \multicolumn{3}{|c|}{ TStaC } & \multicolumn{3}{|c|}{ TSC } \\
\hline & & Max & Min & Average & Max & Min & Average & Max & Min & Average \\
\hline Haluaghat & Thigh & 8.8 & 7.79 & 8.30 & 6.99 & 5.99 & 6.21 & 5.74 & 4.08 & 4.76 \\
\hline Sreepur & Thigh & 8.32 & 7.52 & 7.94 & 6.63 & 6.21 & 6.40 & 5.16 & 4.13 & 4.82 \\
\hline Madhupur & Thigh & 8.47 & 7.42 & 8.15 & 6.25 & 4.98 & 5.43 & 5.26 & 4.29 & 4.56 \\
\hline
\end{tabular}

$\mathrm{TVC}=$ Total Viable Count TStaC $=$ Total Staphylococcal Count TSC $=$ Total Salmonella Count

\subsection{Results of general correlation with TVC, TStaC and TSC in Haluaghat, Sreepur and Madhupur} markets

The result estimated in Figure 4 showed weakly correlated between the total viable count and total staphylococcal count. In this study, total staphylococcal counts were not significantly correlated with total viable count in three upazilas. The regression equation and correlation coefficient values were, $y=-0.2427 \mathrm{x}$ +7.9854 and $\mathrm{R}^{2}=0.0209$ as shown in Figure 1 .

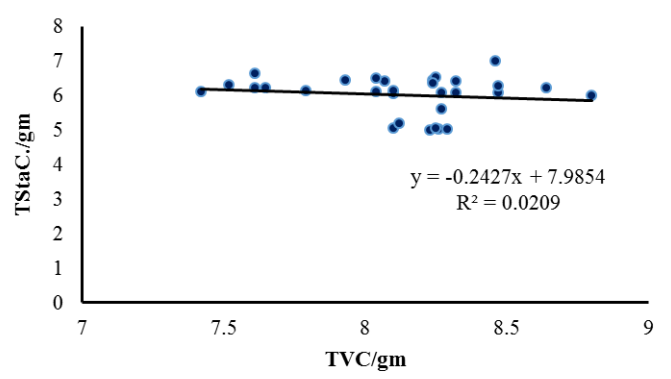

Figure 1. Correlation between total viable count (TVC) and total staphylococcal count (TStaC) in CFU/g meat of three upazilas. 
The result demonstrated in Figure 2, revealed that the regression was positively correlated with Total Viable count and total salmonella count in different upazilas, where correlation coefficient was $\mathrm{R}^{2}=0.0091$ and regression equation was $\mathrm{y}=0.119 \mathrm{x}+3.7461$ respectively.

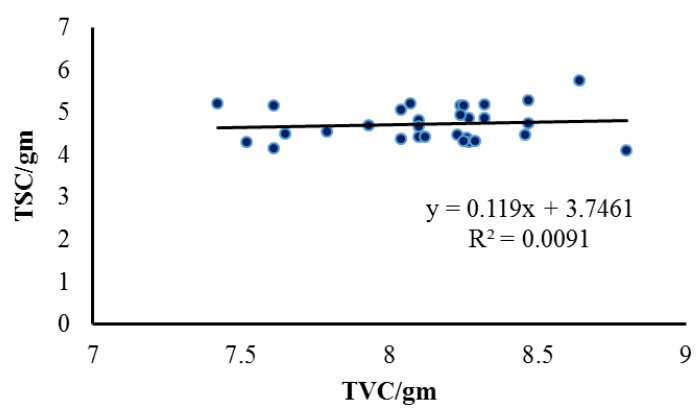

Figure 2. Correlation between total viable count (TVC) and total salmonella count (TSC) in CFU/g meat of three upazila.

The result shown in Figure 3, revealed that the regression was positively correlated with total staphylococcal count and total salmonella count in different upazilas, where correlation coefficient was $\mathrm{R}^{2}=0.2047$ and regression equation was $\mathrm{y}=0.3371 \mathrm{x}+2.6869$ respectively.

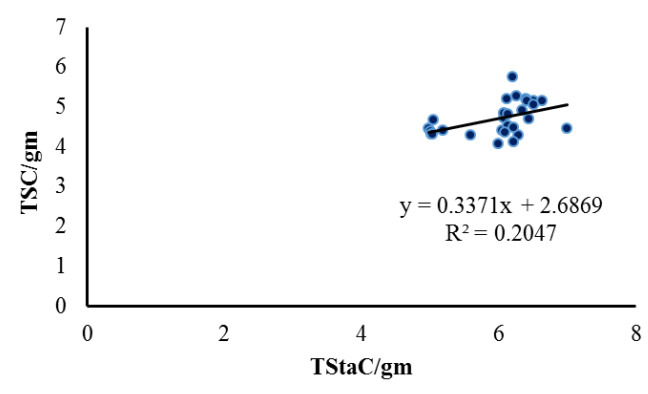

Figure 3. Correlation between total staphylococcal count (TStaC) and total salmonella count (TSC) in CFU/g meat of three upazilas.

\subsection{Microbiological load of buffalo meats of different upazilas markets}

On the basis of TVC buffalo meat sold in different upazilas markets can be evaluated and categorized into two quality groups. Meat sold in Madhupur upazila was relatively of good quality and might be designated as highgrade quality whereas buffalo meat sold at Haluaghat upazila market is of low quality and is designated lowergrade quality. This presents the consideration to evaluate that the meat sold in Sreepur might be medium grade quality. Statistically, on the result of TStaC of buffalo meat of three different upazila markets might be graded into three classes by using Duncan's multiple range tests (DMRT) as shown in Table 2. In the three markets of three district the excellent one was Madhupur market then the next one was Sreepur market and at lastly Haluaghat market respectively analyzed by Duncan's multiple range tests.

\subsection{Isolation of Salmonella spp.}

A total of 30 buffalo thigh meat samples were subjected to isolation and identification of Salmonella spp. A total of 14 Salmonella organisms were identification as presented in Table 4.

Table 4. Total Salmonella spp. isolated from buffalo meat samples from three upazila under three districts of Bangladesh.

\begin{tabular}{ll}
\hline Upazila with district (No. of samples) & No. of Salmonella spp. isolated (\%) \\
\hline Haluaghat; Mymensigh (10) & $6(60)$ \\
Sreepur; Gazipur (10) & $5(50)$ \\
Madhupur; Tangail (10) & $3(30)$ \\
Total (30) & $\mathbf{1 4}(\mathbf{4 6 . 6 7 )}$ \\
\hline
\end{tabular}




\subsection{Results of PCR}

Genus specific (16S rRNA gene) polymerase chain reaction (PCR) was performed. 574bp fragment of targeted gene was amplified successfully. The results of PCR are presented in Figure 4.

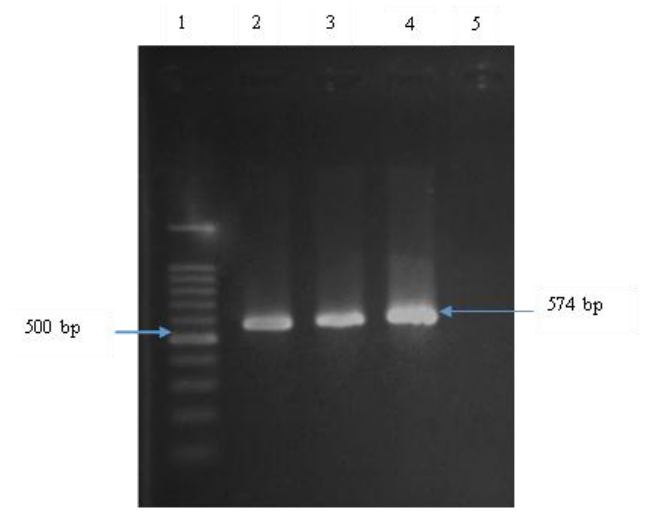

Figure 4. Detection of Salmonella spp. by 16s rRNA gene based PCR. Lane 1: 100 bp DNA marker, lane 2, 3, 4: DNA of Salmonella, Lane 5: Negative control.

\subsection{Results of antimicrobial susceptibility of Salmonella spp.}

All 14 Salmonella isolates were subjected to antimicrobial susceptibility testing against 8 selected antibiotics. The results of susceptibility analysis showed that all the $14(100 \%)$ Salmonella isolates were susceptible to gentamicin, ciprofloxacin and streptomycin. All isolates of Salmonella spp. (n=14, 100\%) were resistant to amoxicillin, whereas $7(50 \%)$ isolates were susceptible, $3(21.42 \%)$ isolates were intermediate and $4(28.57 \%)$ isolates were resistant to azithromycin. Another 4(28.57\%) isolates were susceptible, $3(21.42 \%)$ isolates were intermediate and $7(50 \%)$ isolates were resistant to tetracycline. In case of erythromycin $2(14.28 \%)$ isolates were intermediate and $12(85.71 \%)$ isolates were resistant. Results are presented in Table 5.

Table 5. Antimicrobial susceptibility pattern of Salmonella spp. by disk diffusion method.

\begin{tabular}{llll}
\hline \multirow{2}{*}{ Antimicrobial agents } & \multicolumn{2}{l}{ No. (\%) of Salmonella spp. } \\
\cline { 2 - 4 } & S & I & R \\
\hline Amoxicillin & $0(0.0)$ & $0(0.0)$ & $14(100)$ \\
Azithromycin & $7(50)$ & $3(21.42)$ & $4(28.57)$ \\
Ciprofloxacin & $14(100)$ & $0(0.0)$ & $0.0)$ \\
Erythromycin & $0(0.0)$ & $2(14.28)$ & $12(85.71)$ \\
Gentamicin & $14(100)$ & $0(0.0)$ & $0(0.0)$ \\
Streptomycin & $14(100)$ & - & $0(0.0)$ \\
Tetracycline & $4(28.57)$ & $3(21.42)$ & $7(50)$ \\
Cephradine & $2(14.28)$ & $7(50)$ & $5(35.71)$ \\
\hline
\end{tabular}

$\mathrm{S}=$ Susceptible; $\mathrm{I}=$ Intermediate; $\mathrm{R}=$ Resistance

\subsection{Results of antimicrobial resistance pattern of Salmonella spp.}

The results of antimicrobial resistance patterns of Salmonella spp. are summarized in Table 6. Out of 14 Salmonella spp. 7 (50\%) were resistant to 2 agents E-AMX, 3 (21.42\%) were resistant to 3 agents E-AMX-TE and 2(14.29\%) were also resistant to 3 agents AMX-AZM-TE. Another 2(14.29\%) were resistant to 4 agents AMX-AZM-E-TE.

Table 6. Results of antimicrobial resistance pattern of Salmonella spp.

\begin{tabular}{lll}
\hline Isolates & Resistance profiles & No. of isolates (\%) \\
\hline & No resistance demonstrated & - \\
& Resistant to 2 agents (E-AMX) & $7(50)$ \\
Salmonella spp. $(\mathrm{n}=14)$ & Resistant to 3 agents (E-AMX-TE) & $3(21.42)$ \\
& Resistant to 3 agents (AMX-AZM-TE) & $2(14.29)$ \\
& Resistant to 4 agents (AMX-AZM-E-TE) & $2(14.29)$ \\
& Total & $\mathbf{1 4}(\mathbf{1 0 0})$ \\
\hline
\end{tabular}

AMX=Amoxicillin, AZM=Azithromycin, E=Erythromycin, GEN=Gentamicin, $\mathrm{CIP}=\mathrm{Ciprofloxacin,} \mathrm{CH}=\mathrm{Cephalexin}$, $\mathrm{TE}=$ Tetracycline, $\mathrm{S}=$ Streptomycin 


\section{Discussion}

The present study was designed to assess the microbial load, isolation and identification of Salmonella spp., and determination of antibiotic susceptibility and resistance patterns of Salmonella spp. from raw buffalo meat at abattoirs and retail outlets in different areas of Bangladesh.

The mean value of TVC was observed highest in meat of Haluaghat and lowest in meat of Sreepur. The possible cause of this variation in microbial load might be thought to be due to differences in management and hygienic practices. Observation of the investigation revealed the fact that in case of Sreepur, the hygiene and process of buffalo slaughtering for sale was relatively hygienic in respect of sanitation and handling systems. On the contrary in Haluaghat these are not so, rather the abattoir workers are unskilled, illiterate unaware about hygiene practices. The results obtained were in close agreement with the findings of Hamad et al. (2010). These numbers that were upper than $\log 7 \mathrm{cfu} / \mathrm{gm}$ of meat considered as unacceptable meat for human and same meat products must not be permit to import. The variation of TVC in meats of different upazilas signify the fact that the external and exposed surfaces of buffalo carcass can become easily contaminated after skinning. Similar observations were also noted by Hamad et al. (2010) who found the microbial load in buffalo meat samples of thigh muscle. In present study the values of TVC of different buffalo thigh meat samples exceeded the prescribed maximum microbial limit. ICMSF (1985) recommended that the general viable count of fresh meat tissue at $35^{\circ} \mathrm{C}$ should be less than $\log 6$ per gram. TVC found in meat samples of the present study were a slightly increased than the range as prescribed by International Commission for the Microbiological Specification of food. Bolton (1996) and Hassall (1995) similarly led to the opinion that meat production in Bangladesh took place in a very disorganized way, but due to the non-availability of cold chain the product was sold and consumed without delay, as a result massive contamination if there was, could not enhance meat deterioration and the threat which may arise cannot endanger the health of consumers. Improper de-hiding of the carcass, leading to heavy contamination of meat surfaces by frequent contact with many persons, polluted floors and dirty tools, knives and equipment.

The mean value of TStaC per gram in meats of Haluaghat, Sreepur and Madhupur were $\log 6.21, \log 6.40$ and $\log 5.43 \mathrm{CFU} / \mathrm{gm}$ respectively. These findings have proximal relationship with the findings of Harsojo and Sari (2015). The results of total staphylococcal count in three upazilas were differed significantly. Contamination was found in outer carcass meat. Compared to Harsojo's observation in 2011, the numbers of Staphylococcus spp. obtained in this study for inner carcass are an order of magnitude higher. The high staphylococcal counts in meat of Sreepur might suggest that the carcass were exposed to varied sources of contamination where possible. The lower staphylococcus was recorded in Madhupur maintaining proper hygiene and sanitary measure. The high initial contamination of meat indicates that producers did not give adequate attention to the sanitation and hygiene of the meat sold. Another possibility is that at the time of the transportation and retail in the seller's place, the transporters and the sellers are not concerned about food safety or are not familiar with the Hazard Analysis Critical Control Point (HACCP).

The mean value of TSC per gram in meats of Haluaghat, Sreepur and Madhupur were $\log 4.76, \log 4.82$ and $\log$ 4.56 CFU/gm respectively. The principal source of Salmonella contaminating buffalo thigh meat includes hands of abattoir workers, cloths, wiping cloths, tools of workers, knives, skin, eviscerating reck etc. The organisms have been isolated from 50\% of the apparently normal healthy individuals. In Madhupur the value of TSC in meat was lower than Haluaghat but it was highest in Sreepur. The interpretation of total salmonella count in three different upazilas were not differed significantly $(\mathrm{P}>0.05)$. No positive correlation and significant variation of TSC was found in three different upazilas and in differed buffalo carcass. This signifies the fact that all these meats were more or less handled in the same manner.

Molecular identification and antimicrobial susceptibility of Salmonella spp. was performed in the present study. PCR was performed with genus specific $16 \mathrm{~s}$ rRNA gene (574 bp). For the cultural examination several selective media such as SS and XLD were used simultaneously to culture the organism and isolation of salmonellae which was also used by a number of researchers (Hamad et al., 2010). The colony characteristics of Salmonella spp. found in this study was translucent, black smooth, small round colonies on SS agar, pink color colony with black centre in XLD agar, were similar to the findings of other authors (Elsayed et al.,2014; Harsojo and Sari, 2015; Hamad et al. 2010). In Gram's staining, the morphology of the isolated Salmonella spp. exhibited Gram negative small rod arranged in single or paired which was supported by several authors (Sen and Garode, 2016; Singh et al., 2015; Sychanh et al., 2013). In this study, biochemical tests were performed for the identification of Salmonella spp. which were also used by several researchers (Hamad et al., 2010; Singh et al., 2015). In carbohydrate fermentation test, the isolates that fermented glucose, maltose and produced acid and gas but did not ferment lactose those indicated positive for Salmonellae as was stated by Sen and Garode (2016). The isolates were positive for Methyl Red test but negative for VP test indicating characteristics of Salmonella spp. 
test which was similar with the statement of Hamad et al. (2010). In indole test, all the test isolates ( $\mathrm{n}=14)$ did not develop any red color that indicated the Salmonella spp. The isolates were also negative to indole test and this was similar with the findings of Sychanh et al. (2013). All conditions and results found in the PCR was related by the findings of the several authors (Ziemer and Steadham, 2003; Lin and Tsen, 1996). In this study it was revealed that Salmonella spp. were sensitive to ciprofloxacin, gentamicin and streptomycin. All isolates of Salmonella spp. $(\mathrm{n}=14 ; 100 \%)$ were resistant to amoxicillin, whereas $4(28.57 \%)$ isolates were resistant to azithromycin. Another 4(28.57\%) isolates were susceptible, 3(21.42\%) isolates were intermediate and 7(50\%) isolates were resistant to tetracycline. In case of erythromycin 2(14.29\%) isolates were intermediate and 12(85.71\%) isolates were resistant. This result was similar to the result of Acharya et al. (2010).

\section{Conclusions}

The result demonstrates the fact that the unhygienic and poor sanitary condition under which the meat and meat products were handled and processed was not acceptable from sanitary point of view and it has evidenced clearly the undesirable level of contamination which may have acquired from the environment and agents. Detection of pathogenic Salmonella in buffalo meat samples revealed the fact that the meat sold in abattoir and retail shop may endanger consumer health.

\section{Acknowledgements}

This study was performed in partial fulfillment of the requirements of a M.S. thesis for Mahedi Hasan from the Department of Microbiology and Hygiene, Bangladesh Agricultural University, Mymensingh, Bangladesh.

\section{Conflict of interest}

None to declare.

\section{References}

Acharya A, A Poudel, AK Sah, D Maharjan, S Tibrewal and PK Mandal, 2010. Isolation and Identification of Bacteria from Meat Processing Units of Kathmandu Valley. International Journal of Microbiology and Allied Sciences, 2: 33-37.

Bauer AW, WMM Kirby, JC Sheris and M Truck, 1966. Antibiotic susceptibility testing by a standardized single disk method. Am. J. Clin. Pathol., 45: 225-230.

Bell C and A Kyriakides, 2002. Salmonella; A practical approach to the organism and its control in foods. Cornwall; Blackwell Science Ltd.

Bolton FJ, L Crozier and IK Williamson, 1996. Isolation of E. coli 0157 from raw meat products. Lett. Appl. Microbiol., 23: 317-321.

Centers for Disease Control and Prevention, 2007. Preliminary food net data on the incidence of infection with pathogens transmitted commonly through food -10 States, 2006. MMWR. Morbidity and mortality weekly report 56: 336-339.

Cowan ST, 1985. Cowan and steel's manual for identification of bacteria ( $2^{\text {nd }}$ editon). Cambridge University Press. Cambridge, London.

DLS, 2015. Livestock Economy at a Glance. Department of Livestock Service, Bangladesh.

Elsayed MSA, E Abdeen, MA Akiela, T Farouk, and Zahran, 2014. Real time and conventional PCR for characterization of Salmonella spp. from imported meat to Egypt. Advances in Animal and Veterinary Sciences, 2: $199-203$.

Ercolini D, F Russo, E Torrieri, P Masi and F Villani, 2006. Changes in the spoilage-related microbiota of beef during refrigerated storage under different packaging conditions. Appl. Environ. Microbiol., 72 : 4663-4671.

Faruque MO, MA Hasnath and NU Siddiqe, 1990. Present status of buffaloes and their productivity raised by the small farmers of Bangladesh. Asian J. Appl. Sci., 3: 287-292.

Gill CO, J Bryant and DA Brereton, 2000. Microbiological conditions of sheep carcasses from conventional or inverted dressing processes. J. Food Prot., 63: 1291-1294.

Gould GW and NG Russell, 2003. Major, new and emerging food-poisoning and food spoilage microorganisms. In: Russell and Gould, editors. Food preservatives. 2nd edition, New York: Kluwer Academic/Plenum Publishers. 1-13.

Hamad MA, SYA AL-Dabbagh and N Habra, 2010. Detection of bacteriological contamination in frozen buffalo meat in Syria and Iraq.

Harsojo and SY Sari, 2015. Bacterial diversity in buffalo meat and bowel from traditional market and the sensitivity of some bacteria to irradiation and antibiotics. Atom Indonesia, 41: $79-85$. 
Hassall, 1995. Bangladesh third livestock development project Vol. 2. Meat processing and marketing sector, Annexure, 1: 1-46.

ICMSF, 1985. Microorganism in foods; samples for Microbiological Analysis: Principles and specific applications. Recommendation of the International Commission on Microbiological Specification for Foods. Association of Microbiological Societies. Toronto, University of Toronto Press.

Kariuki S, G Revathi, N Kariuki, J Kiiru, J Mwituria, J Muyodi, JW Githinji, D Kagendo, A Munyalo and CA Hart, 2006. Invasive multidrug-resistant non-typhoidal Salmonella infections in Africa: zoonotic or anthroponotic transmission. J. Med. Microbiol., 55: 585-591.

Komba EVG, EV Komba, EM Mkupasi, AO Mbyuzi, S Mshamu, D Luwumbra, Z Busagwe and A Mzula, 2012. Sanitary practices and occurrence of zoonotic conditions in cattle at slaughter in Morogoro Municipality, Tanzania: implications for public health. Tanzan J. Health Res., 14: 131-138.

Lin CK and HY Tsen, 1996. Use of two targeted oligonucleotides as PCR primers for the specific detection of Salmonella in foods. J. Appl. Bacteriol., 80:659-666.

Lynch M, J Painter, R Woodruff andC Braden, 2006. Surveillance for foodborne- disease outbreaks-United States, 1998-2002. MMWR Morbidity and mortality weekly report 55: 1-34.

NIH, 2006.Food poisoning national institute of health. Medline Plus Medical Encyclopedia F.

Queipo-Ortuño ML, JDD Colmenero, M Macias, MJ Bravo and P Morata, 2008. Preparation of bacterial DNA template by boiling and effect of immunoglobuling as an inhibitor in real-time PCR for serum samples from patients with brucellosis. Clin. Vaccine Immunol., 15: 293-296.

Sen U and AM Garode, 2016. Identification and detection of Salmonella risk assessment from frozen buffalo meat exported from India. J. Bacteriol. Mycol., 2: 1-17

Singh S, DP Kshirsagar, MN Brahmbhatt, JB Nayak and YA Chatur, 2015. Isolation and characterization of salmonella spp. from buffalo meat samples. Buffalo Bulletin, 34: 301-312.

Smith J, 2003. Food borne illness. Report of Center of Diseases Control and Prevention. National Center of Infectious Diseases, USA.

Sychanh T, S Chaunchom, C Pulsrikarn, S Pornreongwong, P Chaichana and S Boonmar, 2013. Salmonella prevalence in slaughtered buffaloes and cattle in champasak province, lao people's democratic republic. Kasetsart J. (Nat. Sci.), 47: 561-570.

Ziemer CJ and SR Steadham, 2003. Evaluation of the specificity of Salmonella PCR primers using various intestinal bacterial species. Lett. Appl. Microbiol., 37: 463-469. 